\title{
Bio-enriched Pleurotus mushrooms for deficiency control and improved antioxidative protection of human platelets?
}

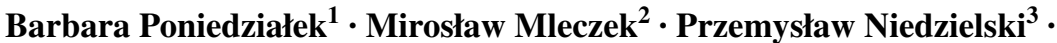 \\ Marek Siwulski $^{4} \cdot$ Monika Gasecka $^{2}$ Lidia Kozak ${ }^{3,5}$ - Anna Komosa ${ }^{6}$. \\ Piotr Rzymski ${ }^{1}$
}

Received: 28 February 2017 / Revised: 4 May 2017 / Accepted: 19 May 2017 / Published online: 27 May 2017

(c) The Author(s) 2017. This article is an open access publication

\begin{abstract}
The study investigated effect of substrate supplementation with Se alone or in combination with $\mathrm{Cu}$ or/and $\mathrm{Zn} \mathrm{Se}$ on (1) the growth of Pleurotus ostreatus and Pleurotus eryngii; (2) elements accumulation in mushrooms; (3) the antioxidant activities of bio-enriched mushroom extracts in human platelets. The accumulation of elements generally increased over concentration gradient reaching its maximum at $1.2 \mathrm{mM}$ for $P$. ostreatus and P. eryngii: (1) over 100 and $80 \mathrm{mg} \mathrm{kg}^{-1}$ of Se, respectively (Se supplementation); (2) over 15 and $30 \mathrm{mg} \mathrm{kg}^{-1}$ of $\mathrm{Cu}$, respectively $(\mathrm{Se}+\mathrm{Cu})$; (3) over 30 and $85 \mathrm{mg} \mathrm{kg}^{-1}$ of $\mathrm{Zn}$, respectively. Se was predominantly accumulated as an organic fraction. Contrary to $P$. eryngii, the $P$. ostreatus biomass decreased with substrate elements concentration but was satisfactory up to $0.9 \mathrm{mM}$ of $\mathrm{Se}, \mathrm{Se}+\mathrm{Cu}$ and $\mathrm{Se}+\mathrm{Zn}$. The $\mathrm{Se}+\mathrm{Cu}+\mathrm{Zn}$ model yielded low biomass and elements accumulation.
\end{abstract}

Electronic supplementary material The online version of this article (doi:10.1007/s00217-017-2921-3) contains supplementary material, which is available to authorized users.

Mirosław Mleczek

mirekmm@up.poznan.pl

1 Department of Environmental Medicine, Poznan University of Medical Sciences, Poznan, Poland

2 Department of Chemistry, Poznan University of Life Sciences, Poznan, Poland

3 Department of Analytical Chemistry, Adam Mickiewicz University, Poznan, Poland

4 Department of Vegetable Crops, Poznan University of Life Sciences, Poznan, Poland

5 Department of Food, Nutrition and Food Contact Materials, Poviat Sanitary and Epidemiological Station, Poznan, Poland

6 1st Department of Cardiology, Poznan University of Medical Sciences, Poznan, Poland
Extracts from mushrooms bio-enriched with $\mathrm{Se}$ and $\mathrm{Se}+\mathrm{Zn}$ (0.6-1.2 $\mathrm{mM})$ revealed significant antioxidant activities in human platelets by ameliorating reactive oxygen species (ROS) and preventing lipid peroxidation. The study demonstrated the potential application of Pleurotus mushrooms as functional food products bio-enriched with essential elements. ROS inhibition by extracts of these mushrooms may be useful in control of platelets activation cascade.

Keywords Pleurotus · Bio-enrichment · Selenium · Copper $\cdot$ Zinc $\cdot$ Human platelets

\section{Introduction}

Mushrooms are increasingly popular as foodstuffs in different world locations owing to their nutritional value and potential medicinal use, extensively evidenced over recent decades. Mushrooms belonging to the genus Pleurotus (higher Basidiomycetes) are, next to Agaricus sp., one of the most important cultivated species worldwide [1] and account for nearly $27 \%$ of global production [2, 3]. Considered as a delicacy, they are rich in B vitamins, polysaccharides and minerals, e.g. potassium, phosphorus, calcium, magnesium and iron [4]. Various pharmacological effects exerted by compounds of Pleurotus, particularly derived from $P$. ostreatus, have been reported and include antiviral antibacterial, antidiabetic, antihypercholesterolic and antiarthritic activities [5-8]. All in all, it appears that Pleurotus mushrooms have particularly high potential as functional foods. Economically-wise, this is also supported by their short growth time, the inexpensive and readily available materials required for their cultivation (e.g. wheat, rice straw, cotton waste or sawdust) and their documented resistance to pathogens and pests [9]. 
Bio-enrichment (bio-fortification) of food is an interesting strategy for delivering nutrients and preventing deficiencies [10,11], and it may be attractive for consumers as it applies products of natural origin, increasingly preferred over synthetic food supplements [12]. However, most attention in this regard is focused on plant-based products [13]. Mushrooms, on the other hand, also have great potential for such use if one considers their ability to uptake and accumulate various elements in their fruiting bodies efficiently $[14,15]$, and their already established place in various national cuisines [16]. Some previous studies have already demonstrated that Agaricus bisporus and Ganoderma lucidum grown on substrates intentionally supplemented with trace elements may reveal significantly increased nutritional value $[17,18]$.

Selenium $(\mathrm{Se})$, zinc $(\mathrm{Zn})$ and copper $(\mathrm{Cu})$ are all known to play pivotal metabolic roles in various biological processes, and their altered status may exert numerous adverse effects in humans. A decreased intake of Se can lead, inter alia, to hair loss, blotchy nails, diarrhoea, garlic breath, gastrointestinal issues and decreased thyroid function [19, 20]. Zn deficiency, on the other hand, has been related to immunosuppression, retardation of physical growth and cognitive function as well as various dermatological problems [21]. Epidemiologicallywise, the worldwide frequency of $\mathrm{Se}$ and $\mathrm{Cu}$ deficiency is not high but can be observed in regions characterized by extremely low content of these elements in the soil and subsequently plant products $[22,23]$. This is particularly the case in some parts of Asia, a continent with a long tradition of mushrooms use, both as food and natural medicines [24]. Zn deficiency is becoming a worldwide problem with approximately $17 \%$ of the human population being at risk [25]. It is therefore essential to maintain the optimal status of these trace metals in humans in order to avoid any manifestation of the above-mentioned harmful effects and to support normal human growth, development and function.

Mushrooms bio-fortified with certain elements may also exert novel properties, e.g. their enrichment with lithium may have a potential use as a medical nutrition therapy in mood modification [26] while enrichment with selenium (Se) enhances the antitumor activities of mushroom polysaccharides [27] and significant immunomodulatory properties of proteins [28]. It has also been shown that $P$. ostreatus and $P$. eryngii enriched simultaneously with $\mathrm{Se}$ and $\mathrm{Zn}$ reveal a greater content of phenolic compounds and that methanolic extracts of these mushrooms exhibited an increased scavenging of radicals in assay with 2,2-diphenyl1-picrylhydrazyl (DPPH) [29]. This would indicate that biofortified mushrooms may have greater antioxidative properties, yet it remained unclear whether they could have any use in the amelioration of oxidative stress in human cells.

The aim of the present study was to investigate whether two edible mushroom species of worldwide popularity, $P$. ostreatus and P. eryngii, can be used in bio-enrichment with $\mathrm{Se}, \mathrm{Cu}, \mathrm{Zn}$ in a single-, double- and triple-element cultivation model, and whether such fortified mushrooms may exert some beneficial antioxidative effects. Specifically, the preventive effect of hot water extracts of fruiting bodies on tert-butyl hydroperoxide (tBHP)-induced oxidative stress in human platelets isolated from healthy donors. It has been evidenced that reactive oxygen species (ROS) play a role in triggering the activation cascade in platelets that involves tethering to the endothelium, rolling adhesion, aggregation and eventually formation of thrombus [30]. Therefore, any antiplatelet effect of bio-enriched mushrooms could play a potentially positive role in the prevention of cardiovascular complications.

\section{Materials and methods}

\section{Experimental design}

The mushrooms of two species $P$. ostreatus and $P$. eryngii were grown on substrates supplemented in four different configurations of trace elements: (1) $\mathrm{Se}$; (2) $\mathrm{Se}+\mathrm{Cu}$; (3) $\mathrm{Se}+\mathrm{Zn}$ and (4) $\mathrm{Se}+\mathrm{Cu}+\mathrm{Zn}$, and final concentrations of $0.1,0.3,0.6,0.9$ and $1.2 \mathrm{mM}$. The control was constituted of mushrooms grown without the addition of any element. The yield included fruiting bodies harvested successively as they matured. Collected material was subjected to analytical determinations of $\mathrm{Se}, \mathrm{Cu}$ and $\mathrm{Zn}$ content in the fruiting bodies. Additionally, speciation analyses were applied to distinguish between the inorganic and organic Se fraction due to distinctive differences in their biological activity. These experiments were designed to choose those cultivation models at which the most efficient bioaccumulation and growth of fruiting bodies was observed. The fruiting bodies from the chosen model were then extracted at high temperature, and extracts were later used to test as regards their ability to attenuate tBHP-induced generation of ROS and lipid peroxidation in human platelets isolated from healthy donors.

\section{Mushroom cultivation and harvesting}

All experimental cultivations were performed in three independent replicates. The substrate for $P$. ostreatus was prepared from wheat straw cut into chaff $4-5 \mathrm{~cm}$ long. The straw for the experiment was moistened to a moisture content of $60 \%$ using distilled water and then pasteurized at $60{ }^{\circ} \mathrm{C}$ for $24 \mathrm{~h}$. The following salts were used in the experiment: sodium selenite $\left[\mathrm{Na}_{2} \mathrm{SeO}_{3}(\mathrm{IV})\right]$, sodium selenate $\left[\mathrm{Na}_{2} \mathrm{SeO}_{4}(\mathrm{VI})\right]$ by Acros Organics (USA), copper(II) selenate $\left(\mathrm{CuSeO}_{4} \cdot 2 \mathrm{H}_{2} \mathrm{O}\right)$ and zinc nitrate hexahydrate $\left[\mathrm{Zn}\left(\mathrm{NO}_{3}\right)_{2} \cdot 6 \mathrm{H}_{2} \mathrm{O}\right]$ by Sigma-Aldrich. These salts were dissolved in such an amount of sterile distilled water sufficient to obtain their appropriate concentration $(0.1,0.3,0.6,0.9$ 
and $1.2 \mathrm{mM}$ for all elements) in the substrate after which they were added to the substrate. Following the addition of the salt solution, the substrate water content reached $70 \%$. The substrate was mixed with grain spawn (on wheat grain) which constituted $3 \%$ in relation to the wet weight of the substrate and placed in bags of perforated foil. Each bag contained $1 \mathrm{~kg}$ of the substrate. Mycelium incubation was conducted at a temperature of $25{ }^{\circ} \mathrm{C}$ and relative humidity of air at $85-90 \%$. Once the substrate was totally covered with the mycelium, it was transferred to the cultivation chamber in which the temperature was maintained at $15-16{ }^{\circ} \mathrm{C}$ and relative humidity of air at $85-90 \%$. The cultivation was additionally irradiated with fluorescent light of $500 \mathrm{~lx}$ intensity for $10 \mathrm{~h}$ a day. The growth facility was aerated in such a way as to maintain $\mathrm{CO}_{2}$ concentration below $1000 \mathrm{ppm}$.

The substrate for P. eryngii was prepared from a mixture of beech sawdust and flax shives (3:1 vol.) which was additionally supplemented with wheat bran to the amount of $20 \%$, corn flour $5 \%$ and gypsum $1 \%$ in relation to the substrate dry matter. The mixture was moistened with distilled water to a moisture content of $45 \%$. The substrate prepared as described above was placed in PP bags and sterilized at a temperature of $121^{\circ} \mathrm{C}$ for $1 \mathrm{~h}$ and was then cooled down to a temperature of $25^{\circ} \mathrm{C}$. Cu, Se and $\mathrm{Zn}$ salts were dissolved in sterile water, and the solution was added to the substrate with intensive blending using a POLYMIX PX-SR $90 \mathrm{D}$ stirrer (Kinematica AG, Switzerland) in an amount that allowed their appropriate concentration in the substrate and, at the same time, making sure that the substrate water content reached $60 \%$. The same concentrations of Se and $\mathrm{Zn}$ salts were applied in the substrate as for P. ostreatus. The substrates with Se and $\mathrm{Zn}$ addition were mixed with grain spawn (on wheat grain) of the examined mushroom species (5\% of substrate weight) and placed in polypropylene bottles of $1 \mathrm{~L}$ volume. Each bottle was filled with $350 \mathrm{~g}$ of the substrate and closed with a cover consisting of a cellulose filter type 338 with a typical retention of $12-15 \mu \mathrm{m}$ and a basic weight of $84 \mathrm{~g} \mathrm{~m}^{-2}$ (Munktell, Germany). The incubation was conducted at a temperature of $25{ }^{\circ} \mathrm{C}$ and air relative humidity of $80-85 \%$ until the substrate became completely covered with mycelium. Next, the covers were removed and placed in the cultivation chamber. For fructification, air relative humidity was maintained at $85-90 \%$ and temperature at $14 \pm 1{ }^{\circ} \mathrm{C}$. The cultivation was additionally irradiated with fluorescent light of $500 \mathrm{~lx}$ intensity for $12 \mathrm{~h}$ a day. The growth facility was aerated in such a way as to maintain $\mathrm{CO}_{2}$ concentration below 1000 ppm.

The mushrooms were collected after their biomass no longer demonstrated further increase. The fruiting bodies were then weighed, dried using an electric drier SLW 53 STD (Pol-Eko, Poland) at $50 \pm 2{ }^{\circ} \mathrm{C}$ for $48 \mathrm{~h}$, weighed again for analysis of dry weight and ground in a Cutting Boll Mill 200 (Retsch GmbH, Germany) for $1 \mathrm{~min}$.

\section{Determination of trace elements}

The powdered mushroom samples were sieved through a $0.02 \mathrm{~mm}$ sieve. $1.000 \pm 0.001 \mathrm{~g}$ of sample was extracted by $1 \mathrm{~mol} \mathrm{~L}^{-1}$ phosphoric acid in an ultrasonic bath at an ambient temperature $(30 \mathrm{~min})$. Samples were then filtered through a paper filter (washed by $200 \mathrm{~mL}$ of water and $20 \mathrm{~mL}$ of phosphoric buffer). Sample $\mathrm{pH}$ was adjusted at $6.0-6.5$ by the addition of $10 \mathrm{~mol} \mathrm{~L}{ }^{-1}$ sodium hydroxide solution, and finally the samples were diluted to $20.0 \mathrm{~mL}$ by a phosphate buffer.

For $\mathrm{Cu}$ and $\mathrm{Zn}$ determination, flame atomic absorption spectrometry (FAAS) SpectrAA 22FS (Varian, Australia) was applied with stoichiometric flame acetylene $\left(2.0 \mathrm{~L} \mathrm{~min}^{-1}\right)$ and air $\left(13.5 \mathrm{~L} \mathrm{~min}^{-1}\right)$. Hollow cathode lamps (Varian) were used with the following parameters for $\mathrm{Cu}$ : wavelength $324.8 \mathrm{~nm}$, slit 0.5 , lamp current $10 \mathrm{~mA}$ and for $\mathrm{Zn}$ : wavelength $213.9 \mathrm{~nm}$, slit 1.0, lamp current $5 \mathrm{~mA}$, both with background correction with a deuterium lamp. The determination limits were $0.1 \mathrm{mg} \mathrm{kg}^{-1}$ with uncertainty about $5.0 \%$ (measured as RSD) for both elements determined.

For Se determination, electrothermal atomic absorption spectrometry (ETAAS) SpectrAA 280Z (Agilent, USA) with Zeeman background correction was applied. A selenium hollow cathode lamp (wavelength $196.0 \mathrm{~nm}$, slit $1.0 \mathrm{~nm}$, current $10 \mathrm{~mA}$ ) was used, and a temperature programme was optimized as follows: drying $85-120^{\circ} \mathrm{C}$ during $55 \mathrm{~s}$; ashing $1000{ }^{\circ} \mathrm{C}$ during $8 \mathrm{~s}$; atomization $2600{ }^{\circ} \mathrm{C}$. Pyrolytic graphite tubes and palladium solution as a chemical modifier ( $10 \mu \mathrm{L}$ of $500 \mathrm{mg} \mathrm{L}^{-1}$ for $20 \mu \mathrm{L}$ of sample) were used. The limit of detection $0.01 \mathrm{mg} \mathrm{kg}^{-1}$ and the uncertainty of results (measured as RSD) at the level of $5.0 \%$ were obtained.

In the case of Se species analysis, hyphenated highperformance liquid chromatography with hydride generation atomic absorption spectrometry detection (HPLCHG-AAS) systems was applied as described previously in detail [31]. The hyphenated analytical system consisted of a Shimadzu liquid chromatograph (LC-10A) equipped with an HPLC pump (LC-10AT), a vacuum degasser unit (GT-104), Rheodyne PEEK valve (IDEX, USA) and an anion-exchange column Supelco LC-SAX1 $(250 \mathrm{~mm}$, $4.6 \mathrm{~mm}$ i.d., resin particle size $5 \mu \mathrm{m}$ ) thermostatted by a column oven (CTO-10ASvp). The chromatographic run was isocratic at $3 \mathrm{~mL} \mathrm{~min}{ }^{-1}$ with an injection volume of $200 \mu \mathrm{L}$. The measurements were performed with a Model SpectraAA 220FS spectrometer (Varian, Australia) equipped with an UltrAA selenium hollow cathode lamp. 
The selenium species $\mathrm{Se}(\mathrm{VI})$ does not form volatile hydride, so in order to receive an analytical signal in the HG-AAS system it was necessary to perform a preliminary reduction of $\mathrm{Se}(\mathrm{VI})$ to $\mathrm{Se}(\mathrm{IV})$. The reduction was carried out on-line by heating the sample $\left(90-100{ }^{\circ} \mathrm{C}\right)$ with the reducing agent: $0.5 \mathrm{~mol} \mathrm{~L}^{-1}$ thiourea solution in $10 \mathrm{~mol} \mathrm{~L}^{-1}$ hydrochloric acid (Kozak 2012). The eluate from the chromatographic column was joined to the stream of the reducing agent (flow rate $1 \mathrm{~mL} \mathrm{~min}^{-1}$ from the peristaltic pump) through a $\mathrm{T}$-shape coupling and directed to the Tygon capillary loop (inner diameter $0.82 \mathrm{~mm}$ ) heated in a water bath. The capillary loop outlet was connected to the hydride generation system. For both analytical systems, PEEK transfer tubing of the eluent from the LC column to the hydride generation unit was inserted into a Tygon sleeve. The continuous hydride generation system (VGA-77, Varian) consisted of a manually controlled, four-channel peristaltic pump with Tygon tubing ( $0.6 \mathrm{~mm}$ i.d.), one reaction coil (PTFE tubing $0.8 \mathrm{~mm}$ i.d., $75 \mathrm{~cm}$ length) and three-way connectors. The gas-liquid separator was made of glass, and the interior dead volume was $3 \mathrm{~mL}$. For the atomization of the selenium hydrides (detected at $196.0 \mathrm{~nm}$ ), a heating controller, an electrothermally heating mantle and a quartz tube (ETC-60, Varian) heated to $900{ }^{\circ} \mathrm{C}$ were used.

A number of validation parameters characterising the analytical method were determined. The limits of detection $0.01 \mathrm{mg} \mathrm{kg}^{-1}$ for both $\mathrm{Se}(\mathrm{IV})$ and $\mathrm{Se}(\mathrm{VI})$ and the uncertainty of results (measured as RSD) at the level of $10 \%$ for both selenium forms were obtained. As it was impossible to estimate the measurement traceability owing to the lack of any certified reference materials for determination of inorganic selenium species, the recovery of each selenium species was measured upon the addition of a standard to the sample. A recovery of $96-105 \%$ of each species was considered as satisfactory.

\section{Mushroom extract preparation}

Homogenized samples of fruiting bodies were extracted in distilled water at the ratio of $1: 10(\mathrm{w} / \mathrm{v})$ at $95{ }^{\circ} \mathrm{C}$ for $30 \mathrm{~min}$. The samples were then cooled to room temperature and centrifuged, and supernatants were sterilized by filtration on $0.22 \mu \mathrm{m}$ syringeless filter devices (Roth). The extracts were kept at $-20{ }^{\circ} \mathrm{C}$ until use.

\section{Human platelet isolation}

Human platelets were isolated from whole blood samples $(6 \mathrm{~mL})$ collected in acid citrate dextrose (ACD) from three healthy donors (screened by physical examination, medical history and initial blood tests), with normal platelet count $\left(150,000-450,000\right.$ cells $\left.\mu \mathrm{L}^{-1}\right)$. The donors (aged 19-22 years old; three females) were non-smoking and normal weighted (BMI 18.5-24.9). Samples were collected at the Regional Centre of Blood and Blood Treatment in Poznan, Poland, according to accepted safeguard standards and legal requirements. Within $20 \mathrm{~min}$ of collection, platelet-rich plasma (PRP) was obtained by centrifugation at $200 \mathrm{~g}$ for $12 \mathrm{~min}$. PRP was transferred into a polypropylene tube, and 1/10 volume $\mathrm{ACD}$ and $100 \mathrm{ng} \mathrm{mL}^{-1}$ prostaglandin E1 was added to prevent platelet activation during isolation. PRP was centrifuged at $900 \mathrm{~g}$ for $15 \mathrm{~min}$, and plasma was aspirated. Platelets were then suspended in $6 \mathrm{~mL}$ of Hepes- $\mathrm{NaCl}_{2}$ buffer (10 mM Hepes, $0.85 \% \mathrm{NaCl}, \mathrm{pH} 7.4$ ) and layered on a discontinuous 10-17\% iodixanol gradient in Hepes/ $\mathrm{NaCl}$ buffer. The gradient was centrifuged at $300 \mathrm{~g}$ for $20 \mathrm{~min}$, and the platelet fraction was collected. Platelets were centrifuged at $900 \mathrm{~g}$ for $15 \mathrm{~min}$, and the resulting pellet was washed and resuspended with $\mathrm{Ca}^{2+}$-free TyrodeHepes buffer (137 mM NaCl, $0.3 \mathrm{mM} \mathrm{NaH}{ }_{2} \mathrm{PO}_{4}, 3.5 \mathrm{mM}$ Hepes, 5.5 mM [D]-glucose, $\mathrm{pH} 7.35)$.

\section{Intracellular reactive oxygen species assay}

Isolated platelets were loaded for $30 \mathrm{~min}$ at $37{ }^{\circ} \mathrm{C}$ in darkness with $20 \mu \mathrm{M}$ of $2^{\prime}, 7^{\prime}$-dichlorofluorescin diacetate (DCFDA; Abcam, UK), a fluorogenic dye that measures hydroxyl, peroxyl and other reactive oxygen species (ROS) activity within the cell. Cells were then washed, pretreated with $10 \mu \mathrm{L}$ mushroom extracts for $30 \mathrm{~min}$, washed again, seeded in black clear bottom 96-well plate and exposed to $10 \mu \mathrm{M}$ tBHP (Abcam, UK) for another $60 \mathrm{~min}$. The negative/positive controls consisted of DCFDA-loaded platelets pretreated with $10 \mu \mathrm{L}$ of Tyrode-Hepes buffer and not exposed/exposed to $10 \mu \mathrm{M}$ tBHP. Fluorescence of DCFDA in all samples was measured kinetically after 15, 30 and $60 \mathrm{~min}$ of incubation using a Synergy HTX multi-mode plate reader (BioTek, USA) at an excitation of $495 \mathrm{~nm}$ and emission of $528 \mathrm{~nm}$. The final results were presented as a percentage of the negative control.

\section{Lipid peroxidation assay}

Lipid peroxidation was analysed using a Lipid Peroxidation (MDA) Colorimetric/Fluorometric Assay Kit (BioVision, UK) by means of malondialdehyde (MDA) equivalents. Isolated platelets were pretreated with $10 \mu \mathrm{L}$ mushroom extracts for $30 \mathrm{~min}$, washed and exposed to $10 \mu \mathrm{M}$ tBHP for another $60 \mathrm{~min}$. The negative/positive controls constituted of platelets pretreated with $10 \mu \mathrm{L}$ of Tyrode-Hepes buffer and not exposed/ exposed to $10 \mu \mathrm{M}$ tBHP. After the experiments, cells were harvested from each well and homogenized on ice in $300 \mu \mathrm{L}$ of provided lysis buffer and centrifuged 
to remove insoluble material. The resulting $200 \mu \mathrm{L}$ of supernatants was transferred to a microcentrifuge tube and supplemented with $600 \mu \mathrm{L}$ of thiobarbituric acid (TBA) to generate an MDA-TBA adduct. To accelerate the reaction, samples were incubated at $95{ }^{\circ} \mathrm{C}$ for $60 \mathrm{~min}$ and the final product was measured colorimetrically at $532 \mathrm{~nm}$. The calculated values were compared to a calibration curve prepared using MDA standard (BioVision, $\mathrm{UK})$. The coefficient of variation $\left(r^{2}\right)$ for the calibration curve was 0.99 . The final results were presented as a percentage of the negative control.

\section{Statistical analysis and calculations}

The results were analysed using STATISTICA 10.0 software (StatSoft, USA). Because the element accumulation and mushroom biomass data met the assumption on Gaussian distribution (analysed with the Shapiro-Wilk test), comparison of element accumulation and yielded biomass between cultivation models was assessed with multivariate analyses of variance (MANOVA) with the Tukey HSD method as a post hoc test. Since the data of platelet ROS concentration and lipid peroxidation had no normal distribution, the Wilcoxon signed-rank test was employed to compare the studied samples with the positive control. $p<0.05$ was considered as statistically significant.

\section{Results and discussion}

\section{Accumulation of trace elements in bio-enriched mushrooms}

The addition of Se to the growth substrate increased its accumulation in the fruiting bodies of both investigated species in a concentration-dependent manner. Greater concentrations were, however, found for P. ostreatus. Nevertheless, Se concentrations were 40-fold higher compared to the control once the substrate overgrown by both species was supplemented with $1.2 \mathrm{mM}$ of Se. It is worth noting that an increase in Se content was over 10-fold for $P$. ostreatus and 20-fold for P. eryngii when the lowest assayed concentration, $0.1 \mathrm{mM}$, was added (Fig. 1). For both species, organic Se had the greatest share for nearly all the studied substrate concentrations (Table 1). P. ostreatus, however, revealed higher concentrations, reaching maximally over $100 \mathrm{mg} \mathrm{kg}^{-1}$ after the substrate had been supplemented with $1.2 \mathrm{mM}$ of Se (Table 1). These findings are in line with previous studies demonstrating the potential of various mushrooms from the Pleurotus genus in the production of food bio-fortified with Se [31, 32].

Compared to mushrooms cultivated on substrates enriched only with Se, the simultaneous addition of Se and $\mathrm{Cu}$ resulted in decreased Se accumulation in both Pleurotus species although this effect was more evident for $P$. eryngii. For this species, Se concentrations did not exceed $20 \mathrm{mg} \mathrm{kg}^{-1}$ regardless of the initial substrate content of trace elements. To compare, for $P$. ostreatus the minimum Se level did not fall below $40 \mathrm{mg} \mathrm{kg}^{-1}$ once the initial concentrations were in the 0.6-1.2 $\mathrm{mM}$ range (Fig. 1). Moreover, greater organic Se levels were observed in $P$. ostreatus. In turn, $P$. eryngii was more effective in $\mathrm{Cu}$ bioenrichment, particularly at the $0.6-1.2 \mathrm{mM}$ concentration range at which the $\mathrm{Cu}$ concentrations in the fruiting bodies exceeded at least $20 \mathrm{mg} \mathrm{kg}^{-1}$ (Fig. 2).

Compared to exclusive enrichment with $\mathrm{Se}$, mushroom cultivation on substrates supplemented with Se in combination with $\mathrm{Zn}$ decreased the Se accumulation only 0.1 and $0.3 \mathrm{mM}$ (P. ostreatus) or $1.2 \mathrm{mM}(P$. eryngii) concentration of elements had been applied. The greatest organic Se levels in fruiting bodies of both species were found in mushrooms growing on the substrate supplemented with
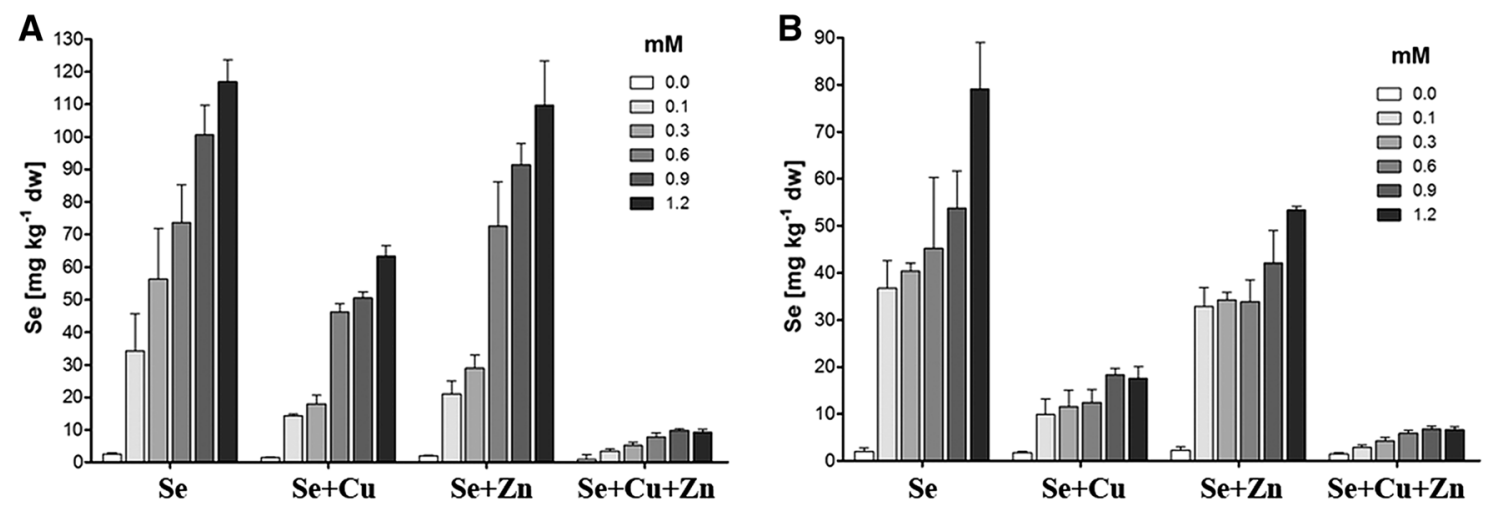

Fig. 1 Concentrations of Se accumulated in the fruiting bodies of Pleurotus ostreatus (a) and P. eryngii (b) growing on variously supplemented substrates. Bars represent mean with standard deviation $(n=3)$ 


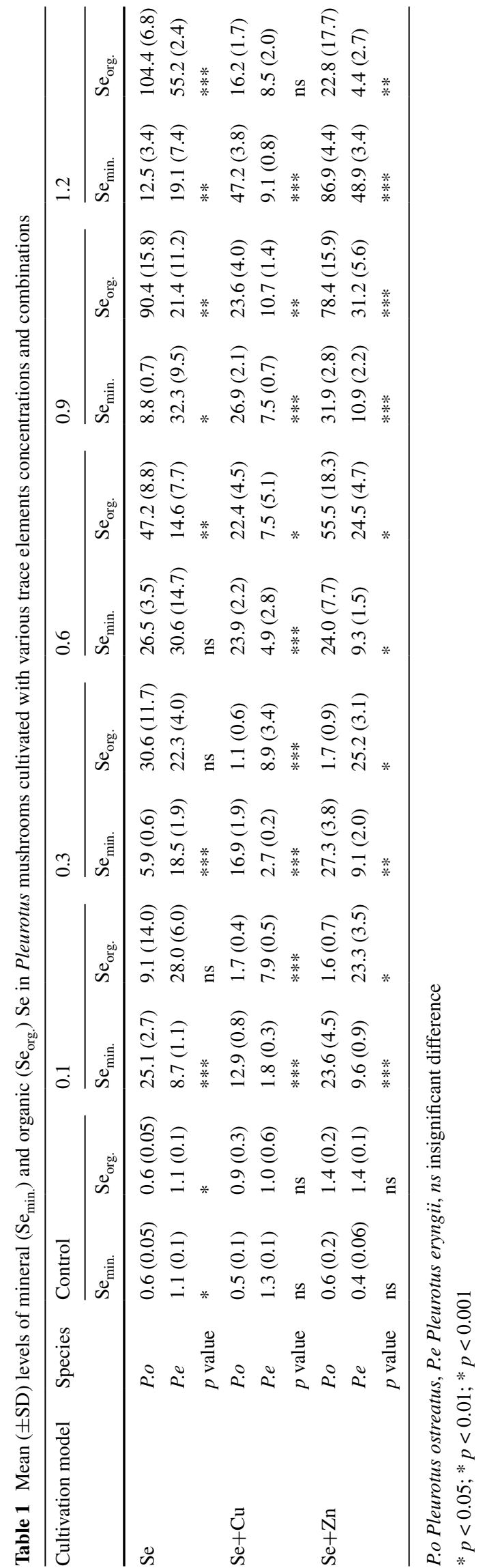

$0.9 \mathrm{mM}$ element concentration. In this combination, the organic Se content reached nearly $80 \mathrm{mg} \mathrm{kg}^{-1}$ for $P$. ostreatus and exceeded $30 \mathrm{mg} \mathrm{kg}^{-1}$ for $P$. eryngii (Table 1). The latter species was, in turn, more effective in $\mathrm{Zn}$ accumulation; the concentrations in the fruiting bodies exceeded at least $45 \mathrm{mg} \mathrm{kg}^{-1}$ after the substrate was supplemented in the 0.6-1.2 $\mathrm{mM}$ element concentration range (Fig. 2).

The observed concentrations of elements in $\mathrm{Se}, \mathrm{Se}+\mathrm{Cu}$ and $\mathrm{Se}+\mathrm{Zn}$ cultivation combinations revealed relatively low variability (with some exceptions), demonstrated by low values of standard deviation (Figs. 1, 2), especially that our experiment was performed in three independent replicates. This, in turn, allows repetitive levels of trace elements to be obtained.

Simultaneous substrate supplementation with $\mathrm{Se}, \mathrm{Cu}$ and $\mathrm{Zn}$ resulted only in a slight increase in Se levels in the fruiting bodies of both, $P$. ostreatus and $P$. eryngii, and usually significantly lower $\mathrm{Cu}$ and $\mathrm{Zn}$ levels compared to the control (Figs. 1, 2). This is most likely due to high competitive sorption of metals from the substrate, an effect observed in various organisms including mushrooms [33, 34]. Due to unsatisfactory Se concentrations, speciation analysis was not performed for this cultivation model.

Considering that the recommended daily allowance (RDA) values were set at $55 \mu \mathrm{g}$ for $\mathrm{Se}, 900 \mu \mathrm{g}$ for $\mathrm{Cu}$ and $11 \mathrm{mg}$ (male) or $8 \mathrm{mg}$ (female) for $\mathrm{Zn}$, for adult individuals [35, 36], the fruiting bodies of $P$. ostreatus and P. eryngii bio-enriched with $\mathrm{Se}$ alone or in combination with $\mathrm{Cu}$ or Zn demonstrate a potentially high nutritional value. However, the partial loss of trace elements during mushroom processing (e.g. washing, drying, cooking) has to be taken into account [14]. The Se in Pleurotus mushrooms has been previously shown to be highly bioaccessible through in vitro studies, particularly in organic form [32]. In the present study, this form accounted for up to $89 \%$ for $P$. ostreatus and $74 \%$ for $P$. eryngii once the inorganic Se salts were added to the substrate at $1.2 \mathrm{mM}$ concentration (Table 1). This is an important finding because the retention of organic forms of $\mathrm{Se}$ (selenocysteine and selenomethionine) is higher than that of inorganic $\mathrm{Se}$ (selenate- $\mathrm{SeO}_{4}{ }^{2-}$ and selenite- $-\mathrm{SeO}_{3}{ }^{2-}$ ) although both were shown to be absorbed in the gastrointestinal tract [37]. Further studies would be required to establish the bioaccessibility of $\mathrm{Cu}$ and $\mathrm{Zn}$ from mushrooms.

The results of the present study indicate that bioenriched Pleurotus mushrooms may help in deficiency prevention. It should, however, be highlighted that an excessive intake of $\mathrm{Se}, \mathrm{Zn}$ or $\mathrm{Cu}$ may also bring about toxic effects in humans [38, 39]. On the other hand, mushrooms are not usually consumed on a daily basis and, moreover, the bio-fortified fruiting bodies of Pleurotus species may be used in adequate amounts (e.g. in form of powder) as a natural ingredient of various food supplements. 


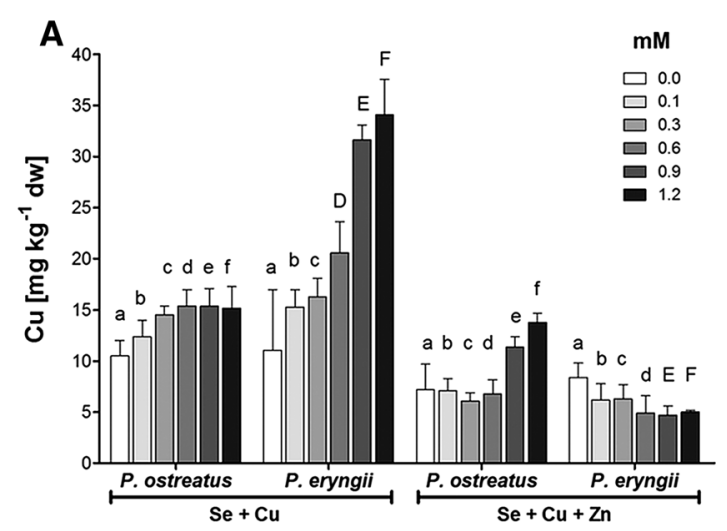

Fig. 2 Concentrations of $\mathrm{Cu}$ (a) and $\mathrm{Zn}$ (b) accumulated in the fruiting bodies of Pleurotus mushrooms growing on variously supplemented substrates. Bars represent mean with standard devia-

\section{Growth of bio-enriched mushrooms}

The growth of the studied mushroom species revealed distinctively different patterns in response to the investigated combinations and concentrations of trace elements. In the case of $P$. ostreatus, the biomass generally decreased with the increasing initial element concentration in the substrate (Fig. 3). This effect was observed on substrates supplemented exclusively with Se but also in combination with $\mathrm{Cu}$ and $\mathrm{Zn}$. Regardless of the combination of metals in the substrate, the lowest yield was found after supplementation

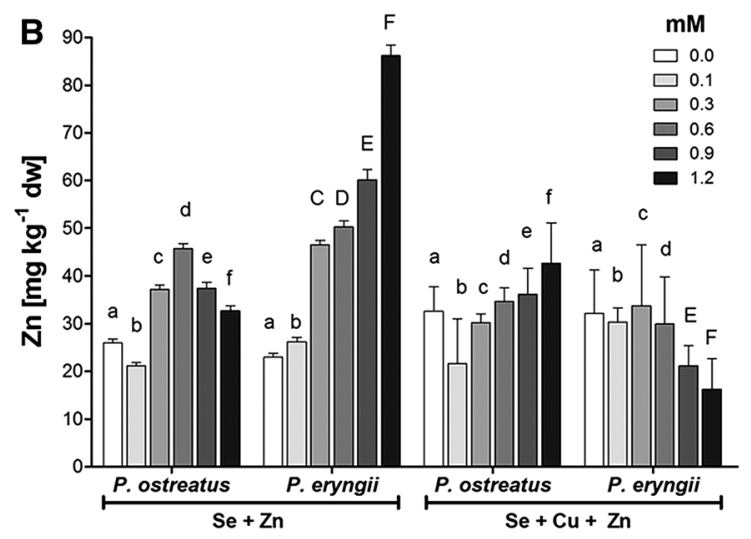

tion $(n=3)$. Significant differences (Student's $t$ test) in metal levels between Pleurotus species in corresponding element combinations and concentrations are indicated by different letter case

of $1.2 \mathrm{mM}$. Nevertheless, with the exception of the $\mathrm{Se}+\mathrm{Cu}+\mathrm{Zn}$ model, the biomass of fruiting bodies did not fall below $100 \mathrm{~g}$ in samples with an initial substrate element concentration up to $0.9 \mathrm{mM}$ (Fig. 3).

Pleurotus eryngii, in turn, exhibited a tendency to increase the biomass with initial concentrations of elements, with the exception of the $\mathrm{Se}+\mathrm{Cu}+\mathrm{Zn}$ model. This was particularly observed for the $\mathrm{Se}+\mathrm{Cu}$ combination for which the greatest biomass production was found after the substrate had been supplemented with $1.2 \mathrm{mM}$ of each element (Fig. 4).
Fig. 3 Biomass of P. ostreatus cultivated on variously supplemented substrates (a) with the trend lines, linear equations and $R^{2}$ values (b). Bars represent mean with standard deviation $(n=3)$. Identical superscript denotes no significant difference $(p>0.05)$ between cultivation models according to Tukey's HSD test (MANOVA) analysed separately for each studied concentration

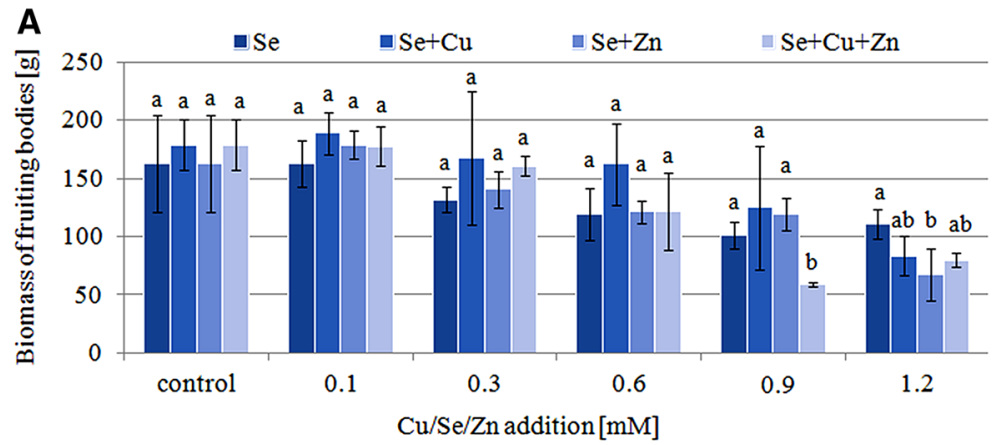

B

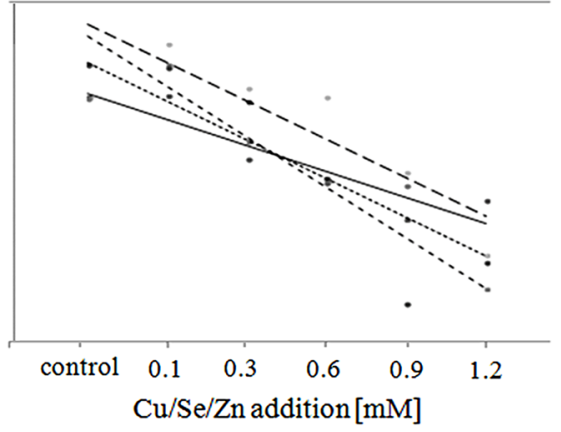


However, no sensory or instrumental measurement was applied; no change in colour or discolouration of the fruiting bodies of $P$. ostreatus and $P$. eryngii was noticeable after the mushrooms were grown on substrates supplemented with Se alone or in combination with $\mathrm{Cu}$ and/ or Zn (Figs. S1, S2). This finding is important from the consumer point of view as it has been shown that changes in the appearance of the food, e.g. the yellowish colour of maize enhanced with vitamin A [40], can be discouraging and lead to a decrease in the commercial value of such food products.

\section{Antioxidant activity of bio-enriched mushrooms}

Antioxidant activities were tested on hot water extracts obtained from fruiting bodies collected from substrates supplemented with $0.6,0.9$ and $1.2 \mathrm{mM}$ concentration of $\mathrm{Se}$, Se and $\mathrm{Cu}$, and $\mathrm{Se}$ and $\mathrm{Zn}$, as these cultivation models yielded the most satisfactory results of element bioaccumulation, organic selenium fraction and mushroom growth.

As observed, extracts of both species grown on substrates not supplemented with any element slightly decreased the intracellular ROS content (Figs. 5, 6) and level of lipid peroxidation (Fig. 6) generated by tBHP in human platelets (Fig. 7). It has been previously shown using in vivo rodent studies that both mushroom species possess antioxidant properties, a phenomenon associated with mushroom-derived polysaccharides [41, 42].
The present study further demonstrates that extracts obtained from mushrooms bio-enriched with Se alone or in combination with $\mathrm{Zn}$ in the tested concentration range $(0.6-1.2 \mathrm{mM})$ enhance their antioxidative effect exerted in platelets. The most significant amelioration of radicals was observed in cells pretreated with extracts from $1.2 \mathrm{mM}$ of the $\mathrm{Se}$ and $\mathrm{Se}+\mathrm{Zn}$ cultivation model with ROS levels decreased by 65.8 and $91.1 \%$ for $P$. ostreatus, respectively (Fig. 5) and by 54.3 and $79.6 \%$ for P. eryngii, respectively (Fig. 6). The counteraction of mushrooms extracts against tBHP-generated ROS resulted in significantly prevented lipid peroxidation in platelets, measured by means of MDA equivalents. The most beneficial effect was observed for extracts obtained from $1.2 \mathrm{mM} \mathrm{Se}+\mathrm{Zn}$ supplementation-compared to the positive control the lipid peroxidation was decreased by $83.5 \%$ for P. ostreatus (Fig. 5) and $67.8 \%$ for P. eryngii (Fig. 6). Peroxidation of lipids is a chain reaction initiated by the hydrogen abstraction or addition of an oxygen radical, resulting in the oxidative damage of polyunsaturated fatty acids. If not terminated fast enough, a decrease in membrane fluidity and in the barrier functions of membranes is induced, final products of peroxidation (predominantly MDA and 4-hydroxy2-nonenal) can induce genotoxicity, and cell death is promoted [43, 44]. Its prevention is thus essential for cell survival and homeostasis.

The observed in vitro effects of mushroom extracts are not only beneficial in view of the prevention of oxidative stress and its potential consequences (e.g. DNA damage,
Fig. 4 Biomass of P. eryngii cultivated on variously supplemented substrates (a) with the trend lines, linear equations and $R^{2}$ values (b). Bars represent mean with standard deviation $(n=3)$. Identical superscript denotes no significant difference $(p>0.05)$ between cultivation models according to Tukey's HSD test (MANOVA) analysed separately for each studied concentration

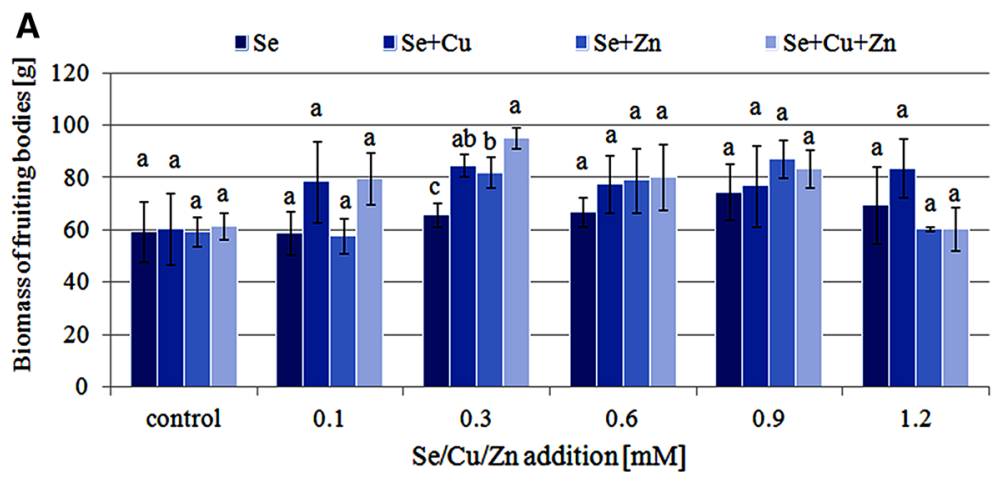

B

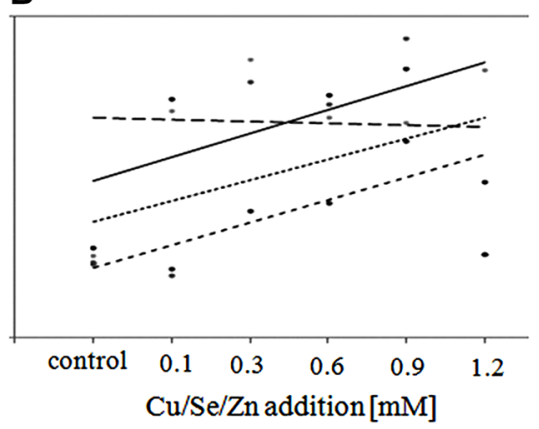




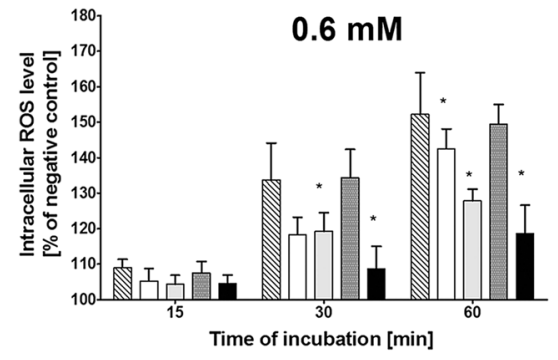

$\triangle$ tBHP $\square$ not enriched + tBHP

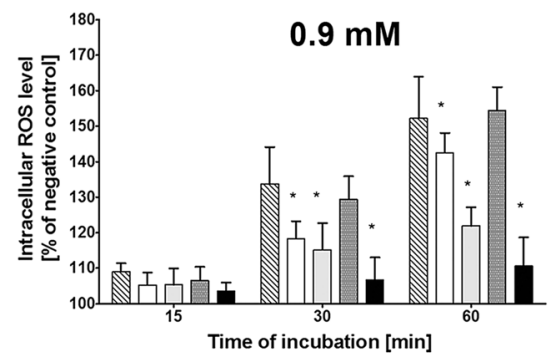

$\mathrm{Se}+\mathrm{tBHP} \quad$ Se \& $\mathrm{Cu}+\mathrm{tBHP}$

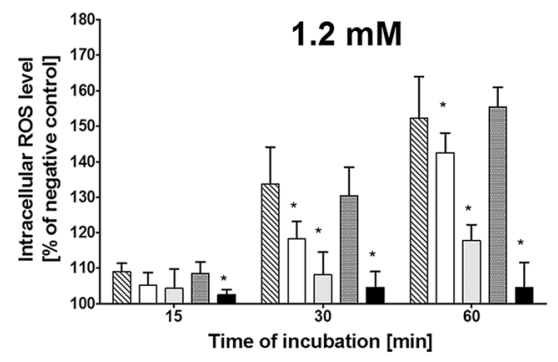

Se \& $\mathrm{Zn}+\mathrm{tBHP}$
Fig. 5 The intracellular ROS concentrations in human platelets exposed for $1 \mathrm{~h}$ to $10 \mu \mathrm{M}$ tBHP and not pretreated with any mushroom extracts (tBHP; positive control), pretreated with extract of unenriched $P$. ostreatus (not enriched + tBHP) and pretreated with extracts of $P$. ostreatus bio-enriched with $0.6-1.2 \mathrm{mM}$ of $\mathrm{Se}(\mathrm{Se}+\mathrm{tBHP}), \mathrm{Se}$ and $\mathrm{Cu}(\mathrm{Se} \& \mathrm{Cu}+\mathrm{tBHP}), \mathrm{Se}$ and $\mathrm{Zn}$ $(\mathrm{Se} \& \mathrm{Zn}+\mathrm{tBHP})$. Bars represent mean \pm SD from three independent experiments corresponding to different donors. Asterisks represent statistically significant difference to the positive control ${ }^{*} p<0.05$; Wilcoxon signed-rank test)

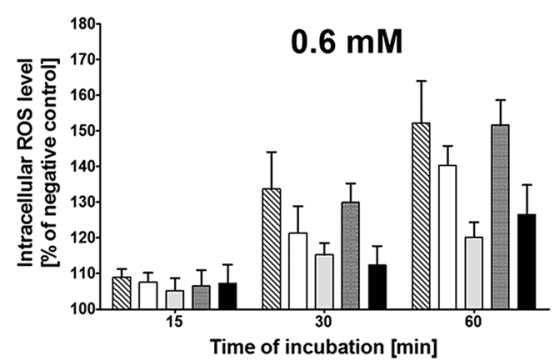

$\triangle$ tBHP $\square$ not enriched + tBHP

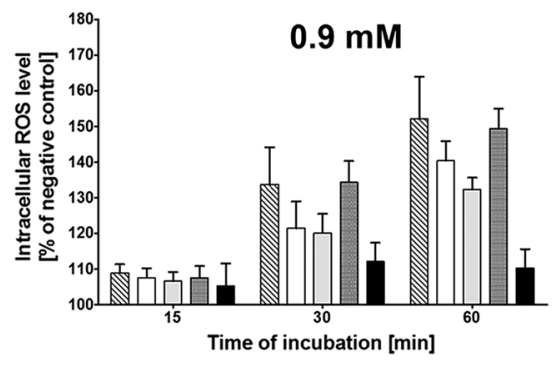

$\mathrm{Se}+\mathrm{tBHP} \square \mathrm{Se} \& \mathrm{Cu}+\mathrm{tBHP}$

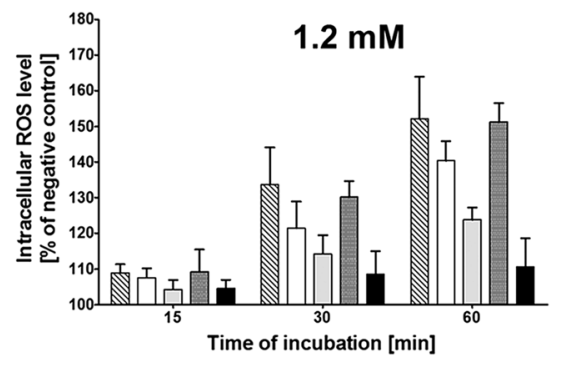

Se \& $\mathrm{Zn}+\mathrm{tBHP}$
Fig. 6 The intracellular ROS concentrations in human platelets exposed for $1 \mathrm{~h}$ to $10 \mu \mathrm{M}$ tBHP and not pretreated with any mushroom extracts (tBHP; positive control), pretreated with extract of unenriched $P$. eryngii (not enriched + tBHP) and pretreated with extracts of $P$. eryngii bio-enriched with $0.6-1.2 \mathrm{mM}$ of $\mathrm{Se}(\mathrm{Se}+\mathrm{tBHP}), \mathrm{Se}$ and $\mathrm{Cu}(\mathrm{Se} \& \mathrm{Cu}+\mathrm{tBHP}), \mathrm{Se}$ and $\mathrm{Zn}$ $(\mathrm{Se} \& \mathrm{Zn}+\mathrm{tBHP})$. Bars represent mean \pm SD from three independent experiments corresponding to different donors. Asterisks represent statistically significant difference to the positive control ${ }^{*} p<0.05$; Wilcoxon signed-rank test)

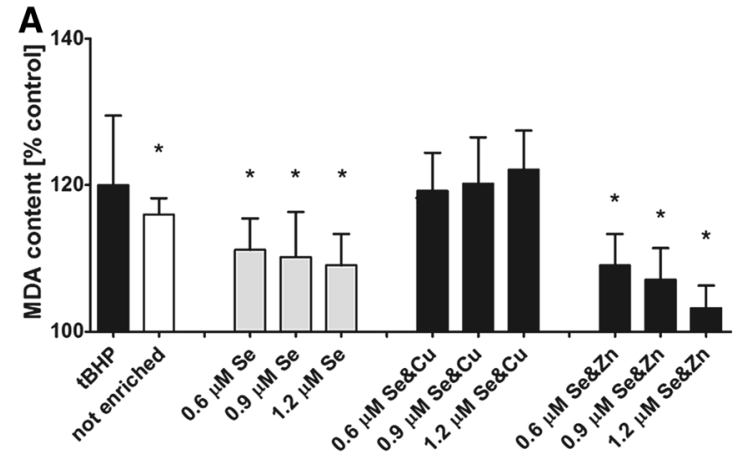

Fig. 7 The level of lipid peroxidation (measured by means of MDA concentration) in human platelets exposed to $10 \mu \mathrm{M}$ tBHP for $1 \mathrm{~h}$ and not pretreated with any mushroom extracts (tBHP; positive control), pretreated with extract of unenriched mushrooms (not enriched + tBHP) and pretreated with extracts of mushrooms bio-enriched with $0.6-1.2 \mathrm{mM}$ of $\mathrm{Se}(\mathrm{Se}+\mathrm{tBHP}), \mathrm{Se}$ and $\mathrm{Cu}$

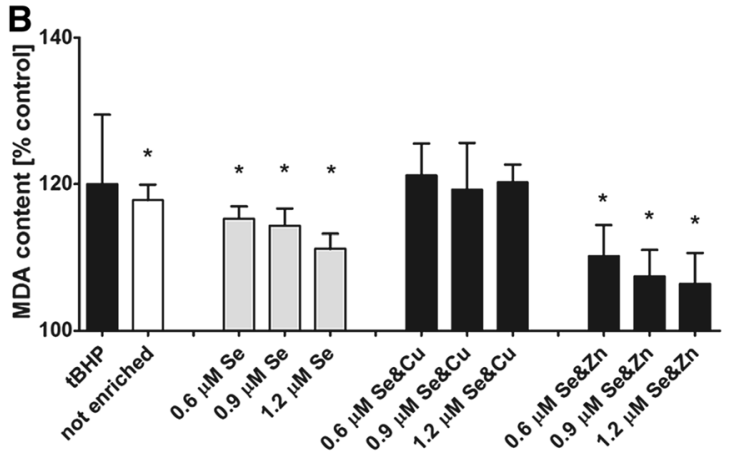

$(\mathrm{Se} \& \mathrm{Cu}+\mathrm{tBHP}), \mathrm{Se}$ and $\mathrm{Zn}(\mathrm{Se} \& \mathrm{Zn}+\mathrm{tBHP})$. a Data for P. ostreatus, $\mathbf{b}$ data for $P$. eryngii. Bars represent mean \pm SD from three independent experiments corresponding to different donors. Asterisks represent statistically significant difference to the positive control $(* p<0.05 ;$ Wilcoxon signed-rank test $)$ 
protein modification, lipid peroxidation) but also in terms of the potential inhibition of platelet activation. Although the present study did not investigate the effect of extracts on platelet aggregation, it is known that ROS may play, along with nitric oxide, adenosine and prostacyclin, a profound role in platelet activation by scavenging nitric oxide (which has a preventive effect on platelet aggregation), triggering tyrosine phosphorylation of $\beta 3$ or supporting the metabolism of collagen and arachidonic acid [23]. Considering that primary mechanism of tBHP action is generation of oxidative stress [45] and that tBHP has been previously demonstrated to support platelet activation cascade [46], it is plausible that the antioxidant properties of mushroom extracts may also prevent platelets from aggregation. Moreover, a recent study demonstrated that an extract of $P$. eous inhibited human platelet activation in vitro, the effect linked to the high mushroom content of phenolic compounds and flavonoids [47]. Their concentrations in P. ostreatus and $P$. eryngii have been previously shown to be significantly increased by substrate supplementation with Se alone and particularly in combination with $\mathrm{Zn}$ [22]. Therefore, it might be interesting to investigate a potential application of bio-enriched mushrooms as antiplatelet agents. There is a clear evidence that dual antiplatelet treatment with aspirin and P2Y12 receptor inhibitors is essential in pharmacological treatment of acute coronary syndromes; it reduces the risk of ischaemic events and improves patients outcome $[48,49]$. Further studies, preferably employing assays such as VerifyNowP2Y12, Multiplate Aggregometry or Light Transmission Aggregometry, are required to evaluate their possible use in prevention of major adverse cardio- and cerebro-vascular ischaemic events such as myocardial infarction, stent thrombosis and stroke [50].

Importantly, extracts obtained from mushrooms cultivated on substrates supplemented with 0.6 and $0.9 \mathrm{mM}$ of Se and $\mathrm{Cu}$ did not prevent generation of ROS (Figs. 5, 6) nor peroxidation of lipids (Fig. 7). This indicates that $\mathrm{Cu}$ can ameliorate the beneficial antioxidative properties of Se, as well as other compounds extractable from Pleurotus mushrooms. However, $\mathrm{Cu}$ (along with $\mathrm{Zn}$ ) is a constituent of cytoplasmic superoxide dismutase $(\mathrm{Cu}, \mathrm{Zn}$ SOD), an important enzyme of the cellular anitoxidant system [51], and at higher concentrations it reveals significant pro-oxidant properties. It was shown that cultivation of Pleurotus sp. in a medium with increased $\mathrm{Cu}^{2+}$ concentration results in enhanced activity of laccases [52]; enzymes performing monoelectronic oxidation of phenols and aromatic or aliphatic amines to corresponding reactive radicals [53]. In summary, the findings of the present study indicate that $P$. ostreatus and $P$. eryngii bioenriched with $\mathrm{Se}$ in combination with $\mathrm{Cu}$ do not reveal any promising antioxidative action, contrary to the other combinations tested.

\section{Conclusions}

The present study highlighted the potential of $P$. ostreatus and $P$. eryngii in the production of food bio-enriched with $\mathrm{Se}$ alone or in combination with $\mathrm{Cu}$ or $\mathrm{Zn}$. Both species were able to grow on supplemented substrates and accumulate significant levels of elements (with a higher share of organic Se fraction) in their edible fruiting bodies. The only unsatisfactory results were obtained in the tripleelement cultivation model-the biomass and accumulated content of elements were low. The study further demonstrated that bio-enrichment with Se alone and in combination with $\mathrm{Zn}$ largely enhances the antioxidant properties of these mushrooms in human platelets as observed by ameliorated ROS generation and prevented lipid peroxidation. These findings indicate that bio-enrichment of Pleurotus mushrooms with the studied elements may not only be a promising strategy in deficiency control but could also have a potential biomedical application, particularly in antiplatelet therapy.

Acknowledgements Piotr Rzymski is supported by the Foundation for Polish Science within the "Start" Program (091.2016).

\section{Compliance with ethical standards}

Funding Piotr Rzymski is supported by the Foundation for Polish Science within the "Start" Program (091.2016).

Conflict of interest All authors declare that they have no conflict of interest

Compliance with ethics requirements This article does not contain any studies with human participants or animals performed by any of the authors.

Open Access This article is distributed under the terms of the Creative Commons Attribution 4.0 International License (http://creativecommons.org/licenses/by/4.0/), which permits unrestricted use, distribution, and reproduction in any medium, provided you give appropriate credit to the original author(s) and the source, provide a link to the Creative Commons license, and indicate if changes were made.

\section{References}

1. FAO STAT (2014) Mushrooms and truffles. Food and Agriculture Organization of the United Nations, Rome

2. Chaubey A, Dehariya P, Vyas D (2010) Seasonal productivity and morphological variation in Pleurotus djamor. Indian J Sci Res 1:47-50

3. Royse DJ (2014) A global perspective on the high five: Agaricus, Pleurotus, Lentinula, Auricularia \& Flammulina. In: Singh M (ed) Proceedings of the 8th international conference on mushroom biology and mushroom products, New Delhi, India, pp 1-6 
4. Dundar A, Acay H, Yildiz A (2008) Yield performances and nutritional contents of three oyster mushroom species cultivated on wheat stalk. Afr J Biotechnol 7:3497-3501

5. Bobek P, Kuniak L, Ozdin L (1993) The mushroom Pleurotus ostreatus reduces secretion and accelerates the fractional turnover rate of very-low-density lipoproteins in the rat. Ann Nutr Metabol 37:142-145

6. Daba AS, Kabeil SS, Botros WA, El-Saadani MA (2008) Production of mushroom (Pleurotus ostreatus) in Egypt as a source of nutritional and medicinal food. WJAS 4:630-634

7. Iwalokun BA, Usen UA, Otunba AA, Olukoya DK (2007) Comparative phytochemical evaluation, antimicrobial and antioxidant properties of Pleurotus ostreatus. Afr J Biotechnol 6:1732-1739

8. Elbatrawy EN, Ghonimy EA, Alassar MM, Wu FS (2015) Medicinal mushroom extracts possess differential antioxidant activity and cytotoxicity to cancer cells. Int J Med Mushrooms $17: 471-479$

9. Sánchez C (2010) Cultivation of Pleurotus ostreatus and other edible mushrooms. Appl Microbiol Biotechnol 85:1321-1337

10. Broadley MR, White PJ, Bryson RJ, Meacham MC, Bowen HC, Johnson SE, Hawkesford MJ, McGrath SP, Zhao FJ, Breward N, Harriman M, Tucker M (2006) Biofortification of UK food crops with selenium. Proc Nutr Soc 65:169-181

11. Hotz C (2009) The potential to improve zinc status through biofortification of staple food crops with zinc. Food Nutr Bull 301(Suppl):S172-S178

12. Kennedy $\mathbf{J}$ (2005) Herb and supplement use in the US adult population. Clin Ther 27:1847-1858

13. Blancquaert D, De Steur H, Gellynck X, Van Der Straeten D (2014) Present and future of folate biofortification of crop plants. J Exp Bot 65:895-906

14. Kalač P, Svoboda L (2000) A review of trace element concentrations in edible mushrooms. Food Chem 69:273-281

15. Mleczek M, Niedzielski P, Kalač P, Siwulski M, Rzymski P, Gąsecka M (2016) Levels of platinum group elements and rareearth elements in wild mushroom species growing in Poland. Food Addit Contam Part A 33:86-94

16. Reis FS, Barros L, Martins A, Ferreira IC (2012) Chemical composition and nutritional value of the most widely appreciated cultivated mushrooms: an inter-species comparative study. Food Chem Toxicol 50:191-197

17. Rzymski P, Mleczek M, Niedzielski P, Siwulski M, Gąsecka M (2016) Potential of cultivated Ganoderma lucidum mushrooms for the production of supplements enriched with essential elements. J Food Sci 81:587-592

18. Rzymski P, Mleczek M, Niedzielski P, Siwulski M, Gąsecka M (2016) Cultivation of Agaricus bisporus enriched with selenium, zinc and copper. J Sci Food Agr 97:923-928

19. Hartikainen H (2005) Biogeochemistry of selenium and its impact on food chain quality and human health. J Trace Elem Med Biol 18:309-318

20. Schomburg L, Köhrle J (2008) On the importance of selenium and iodine metabolism for thyroid hormone biosynthesis and human health. Mol Nutr Food Res 2052:1235-1246

21. Prasad AS (2009) Impact of the discovery of human zinc deficiency on health. J Am Coll Nutr 28:257-265

22. Ge K, Yang G (1993) The epidemiology of selenium deficiency in the etiological study of endemic diseases in China. Am J Clin Nutr 57:259S-263S

23. Rayman MP (2009) Selenoproteins and human health: insights from epidemiological data. Biochim Biophys Acta 1790:1533-1540

24. Pala SA, Wani AH, Bhat MY (2013) Ethnomycological studies of some wild medicinal and edible mushrooms in the Kashmir Himalayas (India). Int J Med Mushrooms 15:211-220
25. Wessells KR, Brown KH (2012) Estimating the global prevalence of zinc deficiency: results based on zinc availability in national food supplies and the prevalence of stunting. PLoS One 7:e50568

26. de Assunção LS, da Luz JM, da Silva Mde C, Vieira PA, Bazzolli DM, Vanetti MC, Kasuya MC (2012) Enrichment of mushrooms: an interesting strategy for the acquisition of lithium. Food Chem 134:1123-1127

27. Shang D, Li Y, Wang C, Wang X, Yu Z, Fu X (2011) A novel polysaccharide from Se-enriched Ganoderma lucidum induces apoptosis of human breast cancer cells. Oncol Rep 25:267-272

28. Min-Chang G, Wei-Hong T, Zhen X, Jie S (2014) Effects of selenium-enriched protein from Ganoderma lucidum on the levels of IL-1 $\beta$ and TNF- $\alpha$, oxidative stress, and NF- $\mathrm{B}$ activation in ovalbumin-induced asthmatic mice. Evid Based Complement Altern Med:182-817

29. Gąsecka M, Mleczek M, Siwulski M, Niedzielski P (2016) Phenolic composition and antioxidant properties of Pleurotus ostreatus and Pleurotus eryngii enriched with selenium and zinc. Eur Food Res Technol 2427:723-732

30. Krötz F, Sohn HY, Pohl U (2004) Reactive oxygen species: players in the platelet game. Arterioscler Throm Vasc Biol 24:1988-1996

31. Niedzielski P, Mleczek M, Siwulski M, Rzymski P, Gąsecka M, Kozak L (2015) Supplementation of cultivated mushroom species with selenium: bioaccumulation and speciation study. Eur Food Res Technol 241:419-426

32. Bhatia P, Aureli F, D'Amato M, Prakash R, Cameotra SS, Nagaraja TP, Cubadda F (2013) Selenium bioaccessibility and speciation in biofortified Pleurotus mushrooms grown on seleniumrich agricultural residues. Food Chem 140:225-230

33. Damodaran D, Vidya Shetty K, Raj Mohan B (2014) Uptake of certain heavy metals from contaminated soil by mushroomGalerina vittiformis. Ecotoxicol Environ Saf 104:414-422

34. Rzymski P, Niedzielski P, Poniedziałek B, Karczewski J (2014) Biosorption of toxic metals using freely suspended Microcystis aeruginosa biomass. Cent Eur J Chem 12:1232-1238

35. Food and Nutrition Board, Institute of Medicine (2001) Dietary reference intakes for vitamin $\mathrm{A}$, vitamin $\mathrm{K}$, arsenic, boron, chromium, copper, iodine, iron, manganese, molybdenum, nickel, silicon, vanadium, and zinc. National Academy Press, Washington, DC, pp 442-501

36. Hu Y, McIntosh GH, Young GP (2012) Selenium-rich foods: a promising approach to colorectal cancer prevention. Curr Pharm Biotechnol 13:165-172

37. Thomson CD, Robinson MF (1986) Urinary and fecal excretions and absorption of a large supplement of selenium: superiority of selenate over selenite. Am J Clin Nutr 44:659-663

38. Yang GQ, Wang SZ, Zhou RH, Sun SZ (1983) Endemic selenium intoxication of humans in China. Am J Clin Nutr 37:872-881

39. Seth R, Yang S, Choi S, Sabean M, Roberts EA (2004) In vitro assessment of copper-induced toxicity in the human hepatoma line, Hep G2. Toxicol In Vitro 18:501-509

40. Nestel P, Bouis HE, Meenakshi JV, Pfeiffer W (2006) Biofortification of staple food crops. J Nutr 136:1064-1067

41. Krishnamoorthy D, Sankaran M (2016) Modulatory effect of Pleurotus ostreatus on oxidant/antioxidant status in 7, 12-dimethylbenz (a) anthracene induced mammary carcinoma in experimental rats - a dose-response study. J Cancer Res Ther 12:386-394

42. Zhang C, Li S, Zhang J, Hu C, Che G, Zhou M, Jia L (2016) Antioxidant and hepatoprotective activities of intracellular polysaccharide from Pleurotus eryngii SI-04. Int J Biol Macromolec 91:568-577

43. Burcham PC (1998) Genotoxic lipid peroxidation products: their DNA damaging properties and role in formation of endogenous DNA adducts. Mutagenesis 13:287-305 
44. Ayala A, Muñoz MF, Argüelles S (2014) Lipid peroxidation: production, metabolism, and signaling mechanisms of malondialdehyde and 4-hydroxy-2-nonenal. Oxid Med Cell Longev 2014:360438

45. Kučera O, Endlicher R, Roušar T, Lotková H, Garnol T, Drahota Z, Cervinková Z (2014) The effect of tert-butyl hydroperoxideinduced oxidative stress on lean and steatotic rat hepatocytes in vitro. Oxid Med Cell Longev 2014:752506

46. Sill JC, Proper JA, Johnson ME, Uhl CB, Katusic ZS (2007) Reactive oxygen species and human platelet GP IIb/IIIa receptor activation. Platelets 18:613-619

47. Suseem SR, Saral M (2015) Inhibition of platelet aggregation and in vitro free radical scavenging activity of dried fruiting bodies of Pleurotus eous. Chin J Integr Med 21:530-536

48. Gasparyan AY, Watson T, Lip GY (2008) The role of aspirin in cardiovascular prevention: implications of aspirin resistance. $\mathrm{J}$ Am Coll Cardiol 51:1829-1843

49. Matetzky S, Shenkman B, Guetta V, Shechter M, Beinart R, Goldenberg I, Novikov I, Pres H, Savion N, Varon D, Hod H (2004) Clopidogrel resistance is associated with increased risk of recurrent atherothrombotic events in patients with acute myocardial infarction. Circulation 109:3171-3175

50. Komosa A, Siller-Matula JM, Lesiak M, Michalak M, Kowal J, Mączyński M, Siniawski A, Mularek-Kubzdela T, Wiśniewski S, Grajek S (2016) Association between high on-treatment platelet reactivity and occurrence of cerebral ischemic events in patients undergoing percutaneous coronary intervention. Thromb Res 138:49-54

51. Poniedziałek B, Rzymski P, Karczewski J (2015) The role of the enzymatic antioxidant system in cylindrospermopsin-induced toxicity in human lymphocytes. Toxicol In Vitro 29:926-932

52. Stajic M, Persky L, Hadar Y, Friesem D, Duletic-Lausevic S, Wasser SP, Nevo E (2006) Effect of copper and manganese ions on activities of laccase and peroxidases in three Pleurotus species grown on agricultural wastes. Appl Biochem Biotechnol 128:87-96

53. Liers C, Ullrich R, Pecyna M, Schlosser D, Hofrichter M (2007) Production, purification and partial enzymatic and molecular characterization of a laccase from the wood-rotting ascomycete Xylaria polymorpha. Enzyme Microb Technol 41:785-793 